\title{
Vitamin D deficiency among older adults in England remains a cause for concern!
}

\author{
V. Hirani, A. Ali and K. Tull \\ Department of Epidemiology and Public Health, Royal Free and University College London Medical School, \\ University College London, London, UK
}

The importance of vitamin D in Ca absorption and metabolism for bone health is well known. Vitamin D deficiency in adults clinically manifests as osteomalacia and osteoporosis. There is also now emerging evidence on how vitamin D may modify the risk of several chronic diseases, such as cancers and CVD and is protective against type 1 diabetes mellitus, multiple sclerosis and rheumatoid arthritis. These effects may be related to newly-proposed biological roles for vitamin D such as having a modulating function for immunity ${ }^{(1)}$ and regulating the growth of many tissues other than bone ${ }^{(2)}$. Concerns about vitamin D deficiency, its role and importance, have been raised by the WHO. In the UK since 1998 government agencies have emphasised the importance of vitamin D in the elderly ${ }^{(3)}$. In 2000 the Health Survey for England (HSE) showed the prevalence of vitamin D deficiency (serum concentrations of $\leq 25 \mathrm{nmol} 25$-hydroxycholecalciferol/l) to be $15 \%$ in women and $10 \%$ in men living in private households. The aim of the present study was to assess vitamin D status of individuals aged $\geq 65$ years, and make comparisons with earlier surveys (HSE 2000 and the National Diet and Nutrition survey (NDNS) data collected in 1994) and examine associations between vitamin D deficiency and risk factors.

A valid vitamin D sample was obtained from 2070 informants (950 men and 1120 women) as part of the HSE 2005, a nationallyrepresentative survey of individuals aged $\geq 65$ years living in private households in England. Analysis included 1160 informants (524 men and 636 women), excluding those on medication that would affect the vitamin D status and those taking vitamin supplements.

The prevalence of vitamin D deficiency ( $\leq 25 \mathrm{nmol} 25$-hydroxycholecalciferol/l) was $20 \%$ in women and $12 \%$ in men. When a higher threshold of $<50 \mathrm{nmol} / \mathrm{l}$ was used (defined as vitamin D insufficiency) $62 \%$ of women and $57 \%$ of men were vitamin D insufficient. Regression analyses showed that women were more vitamin D deficient than men (OR 1.7) and that vitamin D deficiency increased with age (OR 1.7 for those aged 70-74 years and OR 3.2 for those aged $\geq 85$ years), was more likely for those who smoked cigarettes (OR 3.1), was more prevalent in the winter and autumn (OR 2.7) and was associated with poor general health (OR 1.9). Separate analysis for each gender showed that among men vitamin D deficiency was also associated with vitamin $\mathrm{B}_{12}$ deficiency (OR 1.9) and was more likely in those with cancer (OR 2.2). In women deficiency was also $50 \%$ more likely among those in manual social classes and $90 \%$ more likely in obese women $\left(\mathrm{BMI}>30 \mathrm{~kg} / \mathrm{m}^{2}\right)$.

Overall, the results show no significant improvements in vitamin D status in comparison with earlier HSE 2000 results or the NDNS results. Low vitamin D status shows an association with many risk factors and poor general health outcomes. Further action and guidance is required to actively address vitamin D deficiency among the elderly.

1. Hayes CE, Nashold FE, Spach KM \& Pedersen LB (2003) Cell Mol Biol (Noisy-le-Grand) 49, 277-300.

2. Moan J, Lagunova Z \& Porojnicu A (2005) Sunlight, Vitamin D and Health, p. 38 [O Gillie, editor]. http://www.healthresearchforum.org.uk/reports/ sunbook.pdf

3. Department of Health (1998) Nutrition and Bone Health with Particular Reference to Calcium and Vitamin D. Report on Health and Social Subjects no. 49. London: The Stationery Office. 